\title{
LONG-TERM EFFECT OF HCG ON PLASMA TESTOSTERONE IN BULLS
}

\author{
A. SUNDBY, R. TOLLMAN AND W. VELLE \\ Department of Physiology, Veterinary College of Norway, Oslo, Norway*
}

(Received 31st December 1974)

\begin{abstract}
Summary. The spontaneous diurnal variation of peripheral plasma testosterone concentrations in four bulls was established and then the long-term effect of a single intravenous or intramuscular injection of HCG on testosterone levels was studied. Intravenous and intramuscular HGG injections produced, within $\frac{1}{2} \mathrm{hr}$ and $3 \mathrm{hr}$, respectively, a rapid rise of testosterone to levels equivalent to the highest values seen in the diurnal pattern. A second increase of up to $\times 2$ to $\times 3$ the highest values of the diurnal cycle was observed 2 days after the injection of HCG, and the testosterone level remained high for at least 3 to 4 days after plasma levels of HCG were no longer detectable. The pattern of diurnal variation after HCG revealed an attenuation of the extensive spontaneous variation and high levels with only slight fluctuations were maintained.
\end{abstract}

\section{INTRODUCTION}

In Scandinavia, attempts are being made to establish biochemical parameters for use in the early identification of bulls to be selected for breeding purposes. The major objectives of such a breeding programme are increased growth rate and milk production. Testosterone is of importance for growth and feed conversion and one of the lines of research mentioned above is to investigate possible correlations between plasma testosterone concentrations and growth rate in young bulls.

Plasma testosterone concentrations fluctuate spontaneously during the day (Katongole et al., 1971; Sanwal et al., 1974), and single sampling is therefore of little use in the comparison of testosterone levels between different animals. The aim of the present investigation was to attempt to minimize the variations within animals by the use of HCG, and perhaps also to indicate the secretory capacity of the testis for testosterone.

Savard et al. (1961) found a fivefold increase in testosterone levels, measured by a baby chick comb bioassay, in the spermatic vein, but no changes in peripheral plasma testosterone, after intramuscular injection of 20,000 i.u. HCG to bulls on 6 successive days. Lindner (1961) observed a rise in the content of testosterone, determined by a spectrophotometric method, in testis tissue and an

* Postal address: Department of Physiology, Veterinary College of Norway, Postboks 8146, Oslo Dep., Oslo 1, Norway. 
increased output of testosterone into the spermatic vein within 20 min of intravenous administration of 2 to 5 i.u. HCG $/ \mathrm{kg}$ to two bulls. Martin (1964), also using a spectrophotometric method, estimated the increase of testosterone concentrations ( 0 to $10 \mathrm{ng} / \mathrm{ml}$ ) in whole blood from the jugular vein and from the spermatic vein $(\times 7)$ after administering 20,000 i.u. HCG daily for 6 days. Katongole et al. (1971), using a competitive protein-binding assay, observed a fivefold increase in plasma testosterone values $1 \frac{1}{2} \mathrm{hr}$ after intravenous administration of 500 i.u. HCG to a bull.

In the above-mentioned papers, the effect of HCG was studied over short periods. In the present study, the effect of a single intravenous or intramuscular injection of HCG was studied over several days.

\section{MATERIALS AND METHODS}

Four healthy, fertile Norwegian Red bulls, $1 \frac{1}{2}$ to 3 years old and kept at Stensby Artificial Insemination Station, Hamar, Norway, were studied.

The spontaneous diurnal variation of testosterone was first studied in all the bulls. Blood $(15 \mathrm{ml})$ was withdrawn by venepuncture from the jugular vein every hour for $12 \mathrm{hr}$ and collected into heparinized vacutainers (Vacutainer, Becton Dickinson Ltd, France). The blood samples were centrifuged and the supernatant plasma collected and stored at $-15^{\circ} \mathrm{C}$ until analysis.

The same animals were then used to study the effect of a single intravenous (i.v.) or intramuscular (i.m.) injection of 6000 i.u. HCG (Physex: Leo Pharmaceuticals, Denmark) on the concentrations of peripheral plasma testosterone in samples collected twice daily for 4 days after i.v. injection and from the 3 rd to the 7 th day after i.m. injection. The effects of these injections on the spontaneous diurnal variations were further studied by collecting hourly samples for 12 $\mathrm{hr}$ on the day of the i.v. injection and on the 3rd day following the i.m. injection.

Testosterone was measured by the radioimmunoassay method of Sanwal et al. (1974) with some minor modifications. Ovine antiserum (obtained from $\mathrm{Dr}$ K. Martinsson, Veterinary College, Stockholm) was used at a dilution of $1: 20,000$. The specificity of the antiserum accorded with the results of Sanwal et al. (1974) in that of the 23 steroids tested only $5 \alpha$-dihydrotestosterone crossreacted significantly $(40 \%)$. The recovery of testosterone was tested by adding $32 \mathrm{pg}\left[1 \alpha, 2 \alpha-{ }^{3} \mathrm{H}\right]$ testosterone (The Radiochemical Centre, Amersham) to $0 \cdot 1$ or $0.2 \mathrm{ml}$ plasma and extracting testosterone by shaking for $1 \mathrm{~min}$ with $2 \mathrm{ml}$ diethylether. The recovery was $90.7 \pm 3.6 \%$ (S.E.), and this gave a mean recovery correction factor of $1 \cdot 1$. The use of an internal standard was omitted in the assay and the testosterone values were corrected for procedural loss by multiplying by the correction factor. A sample of a control plasma, assayed previously by radioimmunoassay at Aker Hospital, Oslo, was included with each assay run. All the plasma samples were asssayed in duplicate. The precision of the method was estimated for the ranges of 0.8 to $3 \mathrm{ng} / \mathrm{ml}, 3.1$ to $6.4 \mathrm{ng} / \mathrm{ml}, 6.5$ to $10 \mathrm{ng} / \mathrm{ml}$, $10 \cdot 1$ to $15 \mathrm{ng} / \mathrm{ml}, 15 \cdot 1$ to $20 \mathrm{ng} / \mathrm{ml}$ and the variation coefficients were $25 \%$, $21 \%, 4 \%, 4.4 \%$ and $4 \%$ respectively. The HCG in peripheral plasma was measured by a radioimmunoassay involving an antibody produced against 


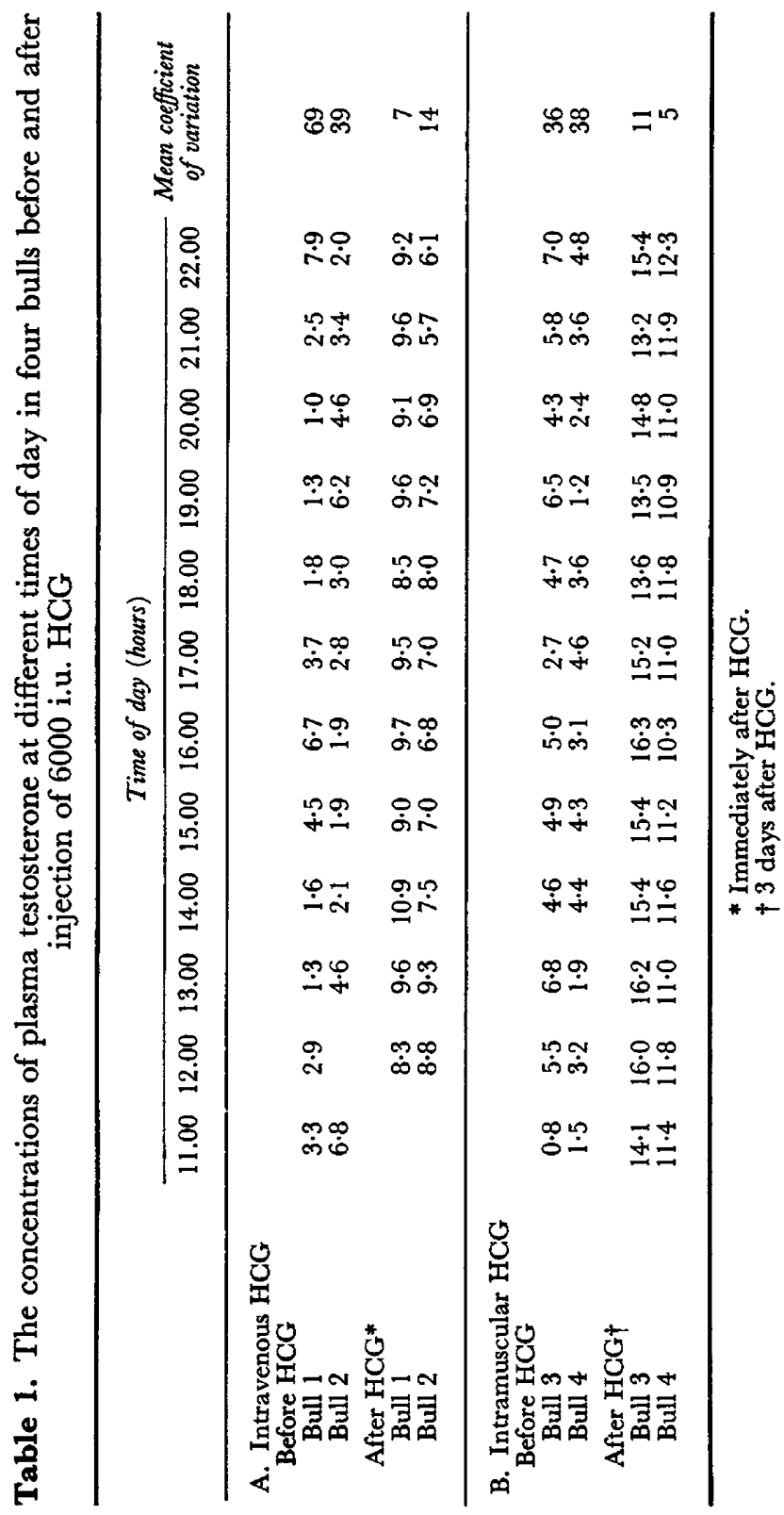


HCG. The cross-reaction of the antibody with human $\mathrm{LH}$ was $100 \%$ and with bovine LH $1.6 \%$. The sensitivity level of this assay was $11 \mathrm{mi} . \mathrm{u} . / \mathrm{ml}$.

\section{RESULTS}

The diurnal plasma testosterone concentrations of the four bulls ranged from 0.8 to $7.9 \mathrm{ng} / \mathrm{ml}$ (Table 1). After administration of HCG the variation was greatly reduced (Table 1). By $\frac{1}{2} \mathrm{hr}$ after i.v. HCG injection, testosterone had risen to levels slightly exceeding the diurnal variation maxima (Text-fig. 1). The levels remained high until the 2nd day after injection when a further rise occurred. The testosterone values continued to rise and were $\times 2 \cdot 2$ the diurnal variation maximum on the 4 th day when sampling was discontinued.
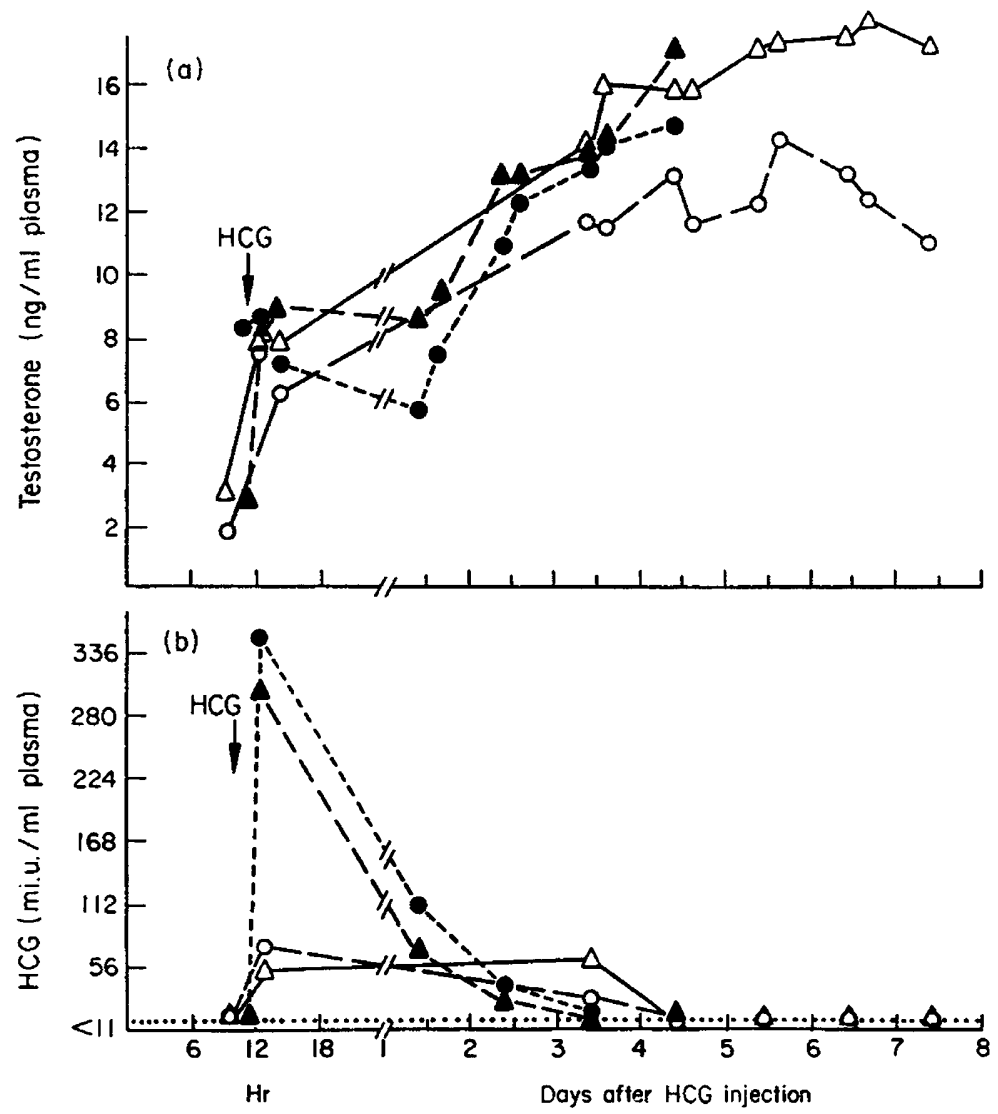

TEXT-FIG. 1. The concentrations of (a) testosterone and (b) residual HCG in the peripheral plasma of four bulls after a single injection of HCG given intravenously $(\Lambda, \bullet)$ or intramuscularly $(\Delta, O)$.

In blood samples first taken $3 \mathrm{hr}$ after i.m. injection of HCG, the testosterone values were raised just above the diurnal variation maxima for these bulls (Text-fig. 1 and Table 1). When sampling was continued on the 3rd day, testosterone levels had risen to more than twice the highest values of the 
pattern before injection. The concentrations continued to rise during the following 4 days and were still high on the 8 th day when sampling was discontinued.

Levels of HCG in the peripheral plasma were maximal in the first sample taken $30 \mathrm{~min}$ after i.v. injection, but decreased to 25 to $30 \%$ within 1 day. The values continued to fall until the 4th day when HGG was no longer detectable (Text-fig. 1).

The HCG levels $3 \mathrm{hr}$ after i.m. injection were 5 to 6 times lower than the maximum levels after i.v. administration. The concentrations declined during the following days and were undetectable on the 4th and 5th days (Text-fig. 1).

\section{DISCUSSION}

The degree of stress experienced by the bulls during venepuncture was subjectively compared with that occurring during collection of blood by means of an indwelling catheter; there appeared to be no differences between the two methods.

The spontaneous diurnal variations of plasma testosterone concentration in the four bulls were similar to those found by Katongole et al. (1971) and Sanwal et al. (1974), but administration of HCG resulted in higher testosterone levels which fluctuated little during the day. The response to HCG varied according to the time at which HCG was administered. In Bull 2, HCG was injected intravenously at a moment when the testosterrone concentration was at a peak, as seen from the sample taken immediately before HCG administration, and there was little further increase, the levels remaining high. When the samples immediately preceding HCG administration were found to have low concentrations of testosterone, i.v. and i.m. injection of HCG was followed by a rise in testosterone to levels slightly above maximum for the normal variation. On the 2nd to 3rd day after HCG was administered a secondary rise in testosterone levels occurred and lasted for 4 to 7 days. The long-term effect of HCG may thus be divided into a primary and secondary response.

From the relationship of the residual HCG in the plasma and the testosterone levels, it can be seen that the primary effect of HCG seems to be associated with the presence of circulating HCG. The secondary effect seems to appear when HCG levels are declining and continues to persist for at least 3 to 4 days after plasma levels of HCG have fallen to undetectable levels.

The long-term effect of a single HCG injection has previously been studied by Zachman (1972) and Andresen (1975). Zachman (1972) reported a marked effect of HCG injection on the secretion of testosterone measured over a 6-day period from 24-hr urine samples of human males between 2 and 20 years of age. Andresen (1975) gave HCG intravenously to boars and noted a primary response in the form of a rise in testosterone $\frac{1}{2} \mathrm{hr}$ after administration and a secondary response resulting in values 2 to 3 times the peak levels of the normal testosterone pattern $28 \mathrm{hr}$ after the injection. The plasma testosterone concentrations declined $50 \mathrm{hr}$ after the HCG injection, unlike the more prolonged effect in bulls noted in this study.

In defining the primary response, two mechanisms may be considered: (1) 
HCG may stimulate the release of testosterone present in the Leydig cells; (2) HCG may stimulate $20 \alpha$-hydroxylase activity, thereby increasing the conversion of cholesterol to 20 $\alpha$-hydroxycholesterol, a rate limiting step in the chain of events leading to the synthesis of testosterone (Hall \& Young, 1968). The secondary effect of HCG may be explained in terms of a general increase in microsomal production of enzymes involved in the synthesis of testosterone. Samuel \& Helmreich (1956) found a prolonged increase in the activity of $3 \beta$-hydroxysteroid dehydrogenase when HCG was given to mice. Shikita \& Hall (1967) observed an increase within $48 \mathrm{hr}$ in the rat testis of 17-20 desmolase, another microsomal enzyme of importance for biosynthesis of testosterone.

When the experiment was planned, the effect of HCG was not expected to be as prolonged as that subsequently observed and in current experiments we are following the effects of HCG over a longer period.

\section{ACKNOWLEDGMENTS}

This investigation was financially supported by the Agricultural Research Council of Norway (NKJ Project No. 22). Thanks are due to Dr P. Torjussen, Aker Hospital, Oslo, who measured plasma HCG levels.

\section{REFERENCES}

ANDRESEN, $\emptyset$. (1975) $5 \alpha$-Androstenone in peripheral plasma in pigs, diurnal variation in boars, effects of intravenous HCG administration and castration. Acta endocr., Copenh. 78, 385-391.

HALl, P.F. \& YouNG, D.G. (1968) Site and action of trophic hormones upon the biosynthetic pathways to steroid hormones. Endocrinology 82, 559-568.

KAtongole, V.B., NAFTolin, F. \& ShORT, R.V. (1971) Relationship between blood levels of luteinizing hormone and testosterone in bulls, and the effects of sexual stimulation. F. Endocr. 50, 457-466.

LiNDNER, H.R. (1961) Androgen and related compounds in the spermatic vein blood of domestic animals. F. Endocr. 23, 139-159.

Martin, R.P. (1964) Steroid pattern in bulls. Colo. St. Univ. Biota pp. 9-17.

Samuel, L.T. \& Helmreich, M.L. (1956) The influence of chorionic gonadotrophin on the $3 \beta$-ol dehydrogenase activity of testes and adrenals. Endocrinology 58, 435-442.

SAnwal, P., SundBy, A. \& Edevist, L.E. (1974) Diurnal variation of peripheral plasma levels of testosterone in bulls measured by a rapid radioimmunoassay procedure. Acta vet. scand. 15, 90-99.

Savard, K., Mason, N.R., Ingram, J.T. \& Gassner, F.X. (1961) Androgens of bovine spermatic venous blood. Endocrinology 69, 324-330.

Shikita, M. \& HaLL, P.F. (1967) The action of human chorionic gonadotrophin in vivo upon microsomal enzymes of immature rat testis. Biochim. biophys. Acta 136, 484-497.

Zachman, M. (1972) The evaluation of testicular endocrine function before and in puberty. Acta endocr., Copenh., Suppl. 164, 1-94. 